\title{
eCOti
DiAno
}

Revista Mídia e Cotidiano

ISSN: 2178-602X

Artigo Seção Temática

Volume 15, Número 3, set./dez. de 2021

Submetido em: 20/07/2021

Aprovado em: 21/09/2021

\section{Desinformação, antivacina e políticas de morte: o mito (d)e virar jacaré}

Disinformation, antivaccine and politics of death: the myth of becoming an alligator

\section{Desinformación, antivacunas y política de la muerte: el mito (d)y convertise en un caimán}

\author{
Josenildo Soares BEZERRA ${ }^{1}$ \\ Madja Elayne da Silva Penha MAGNO² \\ Carolina Toscano MAIA ${ }^{3}$
}

\section{Resumo}

Neste artigo propomos uma reflexão sobre como a desinformação (WARDLE; DERAKSHAN, 2017) e os movimentos antivacina (VASCONCELLOS-SILVA; CASTIEL, 2020) dificultam o combate à pandemia da Covid-19, principalmente quando chancelados por agentes públicos, dada a sua visibilidade e influência na esfera social (SOARES JÚNIOR, 2020; RECUERO et. al., 2021). Assim, analisamos o pronunciamento do presidente da república, Jair Bolsonaro, em que associa a vacinação contra a doença ao mito de virar jacaré. Entendendo o discurso a partir de sua materialidade discursiva, utilizamos uma perspectiva foucaultiana (FOUCAULT, 2001; $2005 ; 2008 ; 2014)$, em uma vertente biopolítica e de seus dispositivos de segurança.

Palavras-chave: Desinformação. Antivacina. Biopolítica. Discurso.

\begin{abstract}
In this article we propose a reflection on how misinformation (WARDLE; DERAKSHAN, 2017) and antivaccine movements (VASCONCELLOS-SILVA; CASTIEL, 2020) hinder the fight against the Covid-19 pandemic, especially when sanctioned by public agents, given their visibility and influence in the social sphere (SOARES JÚNIOR, 2020; RECUERO et. al., 2021). Thus, we analyze the statement of the president of the republic, Jair Bolsonaro, in which he associates vaccination against

\footnotetext{
${ }^{1}$ Doutor em Estudos da Linguagem (UFRN). Professor do Programa de Pós-Graduação em Estudos da Mídia (PPgEM) na Universidade Federal do Rio Grande do Norte (UFRN). E-mail: soares.bezerra@gmail.com. ORCID: 0000-0001-9324-6664. Universidade Federal do Rio Grande do Norte (UFRN). E-mail: madjamagno@gmail.com. ORCID: 0000-0002-6681-0538.

${ }^{3}$ Mestranda em Estudos da Mídia pelo Programa de Pós-Graduação em Estudos da Mídia (PPgEM) na Universidade Federal do Rio Grande do Norte (UFRN). E-mail: caroltmaia@gmail.com. ORCID: 00000001-9825-1948.
}

2 Doutoranda em Estudos da Mídia pelo Programa de Pós-Graduação em Estudos da Mídia (PPgEM) na
\end{abstract}


the disease to the myth of turning alligator. Understanding the discourse from its discursive materiality, we use a foucauldian perspective (FOUCAULT, 2001; 2008; 2014), in a biopolitical aspect and its security devices.

Keywords: Disinformation. Antivaccine. Biopolitics. Discourse.

\section{Resumen}

En este artículo proponemos una reflexión sobre cómo la desinformación (WARDLE; DERAKSHAN, 2017) y los movimientos antivacunas (VASCONCELLOS-SILVA; CASTIEL, 2020) dificultan la lucha contra la pandemia de Covid-19, especialmente cuando son sancionados por agentes públicos, dada su visibilidad e influencia en la esfera social (SOARES JÚNIOR, 2020; RECUERO et. al., 2021). Así, analizamos la declaración del presidente de la República, Jair Bolsonaro, en la que asocia la vacunación contra la enfermedad al mito de convertirse en un caimán. Entendiendo el discurso desde su materialidad discursiva, utilizamos una perspectiva foucaultiana (FOUCAULT, 2001; 2008; 2014), en un aspecto biopolítico y sus dispositivos de seguridad.

Palabras clave: Desinformación. Antivacunas. Biopolítica. Discurso.

\section{Introdução}

A desinformação e os movimentos antivacina dificultam o combate à pandemia da Covid-19, uma vez que a sociedade convive com o excesso de informações, em um cenário em que ainda permanecem dúvidas sobre a transmissão do vírus, sintomas da doença, vacinação, entre outros aspectos. Além disso, estratégias discursivas negacionistas podem ser utilizadas para reforçar a ambiência de descaso à vida, configurada por uma necropolítica, uma política de morte, idealizada de forma propositada a fim de atender interesses ilegítimos próprios ${ }^{4}$. Em artigos que problematizam aspectos relacionados à pandemia, é possível identificar a preocupação com esse tipo de conteúdo e sua influência no cumprimento de medidas preventivas à infecção, assim como na adesão da população à vacinação.

Couto et. al. (2021) discutem o paradoxo da hesitação e do clamor pela vacina contra a Covid-19. Para elas, a infodemia que cerca a doença e a hesitação vacinal refletem a tensão entre o risco validado e o risco percebido de modo subjetivo, reforçado pela crise de confiança na ciência. Assim, as percepções de risco e adesão extrapolaram

4 Disponível em: <https://www1.folha.uol.com.br/poder/2021/06/exclusivo-governo-bolsonaro-pediupropina-de-us-1-por-dose-diz-vendedor-de-vacina.shtml>. Acesso em: 23 de set. 2021. 
aspectos racionais, podendo ser associadas a valores e crenças conformados por dimensões política, econômica e sociocultural.

Considerando-se a complexidade, a diferenciação e a desigualdade nas sociedades contemporâneas, há uma enorme distância entre aqueles que apostam na gestão individual tanto do risco de contrair o vírus como da condição para enfrentar a doença (optando por desconsiderar medidas sanitárias de distanciamento físico e isolamento voluntário), e aqueles que ignoram ou descumprem as normativas por falta de maiores esclarecimentos sobre o risco de adoecer e/ou morrer e sobre o seu papel na corresponsabilização do enfrentamento desta crise epidêmica. (COUTO et. al., 2021, p. 6).

Em relação à desinformação, Barcelos et. al. (2021) analisam as informações falsas disseminadas durante os primeiros seis meses da pandemia no Brasil e indicam que esse tipo de conteúdo é associado a posicionamentos políticos, a desinformação sobre número de casos e óbitos, assim como a medidas de prevenção e de tratamento, incluindo a questão da vacinação. Eles destacam que os principais veículos de divulgação foram o WhatsApp e o Facebook, com maior alcance nas regiões Sudeste e Nordeste do país. "As fake news disseminadas pelos meios digitais relacionadas à Covid-19 tem o potencial de influenciar o comportamento da população, prejudicando sua adesão aos cuidados comprovados pela ciência" (BARCELOS et. al., 2021, p. 5).

Para Caponi (2020), a reflexão sobre a pandemia no cenário nacional está associada ao negacionismo e à razão neoliberal. Ela enfatiza que diante das negativas da gestão presidencial sobre o isolamento social, medida reconhecida pela OMS como eficaz na prevenção da infecção, "[...] a oposição não é cuidar da vida ou cuidar da economia, trata-se, pelo contrário, de uma escolha biopolítica entre proteger a vida ou expor à morte" (CAPONI, 2020, p. 219).

Neste artigo, propomos a reflexão sobre a desinformação na pandemia da Covid19, observando as suas características de produção e circulação, assim como implicações para a sociedade. Também discutimos a articulação de movimentos antivacina, enfatizando o agravamento de recusa ao imunizante a partir da chancela de agentes públicos, dada a sua visibilidade e influência na sociedade. E, finalmente, realizamos uma análise de um trecho do pronunciamento do presidente Jair Bolsonaro, em 17 de 


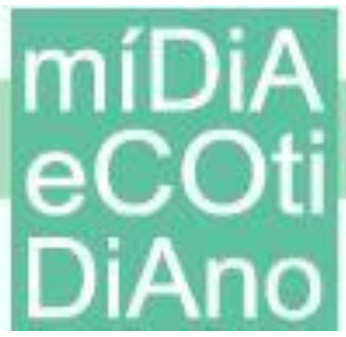

dezembro de 2020, que ficou conhecido pelo ineditismo da fala em que a vacina transformaria pessoas em jacaré. Entendendo o discurso a partir de sua materialidade discursiva, utilizamos uma perspectiva foucaultiana, em uma vertente biopolítica, e seus dispositivos de segurança, entrepondo a prática analítica aos pressupostos teóricosmetodológicos.

\section{A desinformação na pandemia da Covid-19}

Em março de 2020, a Organização Mundial da Saúde (OMS) anunciou a pandemia da Covid-19, doença respiratória causada por um vírus identificado como SarsCov- $2^{5}$. A infecção foi localizada inicialmente em Wuhan, uma província de Hubei, na China, que rapidamente alcançou outros países em todo o mundo. Segundo dados da Universidade Johns Hopkins, até o dia 20 de julho de 2021, foram registrados 191.090.003 casos de contaminação e 4.099.338 mortes pela doença em 191 países/regiões, e, especificamente, no Brasil, foram contabilizados 19.391 .845 casos e 542.756 óbitos $^{6}$.

Além dos números estarrecedores associados ao vírus e das implicações alarmantes da pandemia para a sociedade, a preocupação com a circulação de informações imprecisas ou falsas sobre a doença também é evidenciada. Para a Organização PanAmericana da Saúde (OPAS) e a OMS, o surto de Covid-19 e a resposta a ele são acompanhados pelo que caracterizam como infodemia, "um excesso de informações, algumas precisas e outras não, que tornam difícil encontrar fontes idôneas e orientações confiáveis quando se precisa" (OPAS, 2020, p. 2) e desinformação, definida como "uma informação falsa ou imprecisa cuja intenção deliberada é enganar" (OPAS, 2020, p. 2), conteúdos sinalizados por sua capacidade de prejudicar a saúde humana ${ }^{7}$.

Wardle (2017) indica que a desinformação corresponde à criação e compartilhamento deliberados de informações reconhecidas como falsas, com o objetivo de causar dano a algo ou alguém. Em sentido complementar, destaca-se que, entre os

\footnotetext{
5 Disponível em: <https://agenciabrasil.ebc.com.br/geral/noticia/2020-03/organizacao-mundial-da-saudedeclara-pandemia-de-coronavirus $\rangle$. Acesso em: 4 de jun. 2021.

${ }^{6}$ Disponível em: <https://coronavirus.jhu.edu/map.html>. Acesso em: 4 de jun. 2021.

${ }^{7}$ Disponível em: <https://iris.paho.org/bitstream/handle/10665.2/52054/Factsheet-

Infodemic_por.pdf?sequence=5>. Acesso em: 20 de jul. 2021.
} 
diferentes tipos de desinformação, os conteúdos que afetam as emoções das pessoas possuem amplo alcance.

O conteúdo problemático mais bem-sucedido é aquele que toca nas emoções das pessoas, encorajando sentimentos de superioridade, raiva ou medo. Quando a maioria das plataformas sociais é projetada para que as pessoas as executem publicamente através de curtidas, comentários ou compartilhamentos, é fácil entender por que o conteúdo emocional viaja tão rapidamente e amplamente, mesmo quando vemos uma explosão de organizações de verificação e desmistificação de fatos. (WARDLE; DERAKSHAN, 2017, p. 7, tradução nossa) ${ }^{8}$.

A Aos Fatos, agência checadora de fatos, realizou uma análise das informações falsas sobre a pandemia que circularam nas mídias sociais, onde foi possível identificar que em três meses, de janeiro a abril de 2020, a desinformação foi de cura milagrosa da doença à politização do isolamento social no Brasil ${ }^{9}$. De acordo com a agência, os aspectos sanitários predominaram nos conteúdos analisados (57\% das verificações sobre o vírus no período), mas o teor político das postagens enganosas verificadas foi acentuado no mês de abril de 2020, acompanhando a evolução de casos de contaminação e de mortes pela doença no país (92\% das checagens publicadas no intervalo). "Entre elas, destaca-se a informação falsa de que a OMS teria recuado das recomendações de isolamento social, adotando uma linha de defesa da economia similar à apoiada pelo presidente Jair Bolsonaro" (AOS FATOS, 2020).

Considerando as verificações de fatos realizadas pela agência Lupa ao longo do ano de 2020, afirma-se que o presidente Jair Bolsonaro fez diversas declarações falsas sobre a pandemia da Covid- $19^{10}$. Como exemplo, indica-se o negacionismo da gravidade

\footnotetext{
${ }^{8}$ The most 'successful' of problematic content is that which plays on people's emotions, encouraging feelings of superiority, anger or fear. When most social platforms are engineered for people to publicly 'perform' through likes, comments or shares, it's easy to understand why emotional content travels so quickly and widely, even as we see an explosion in fact-checking and debunking organizations (WARDLE; DERAKSHAN, 2017, p. 7).

${ }^{8}$ Disponível em: <https://www.aosfatos.org/noticias/em-tres-meses-desinformacao-sobre-covid-19-foi-decura-milagrosa-a-politizacao-do-isolamento/>. Acesso em: 4 de jun. 2021.

${ }^{9}$ Disponível em: <https://www.aosfatos.org/noticias/em-tres-meses-desinformacao-sobre-covid-19-foi-decura-milagrosa-a-politizacao-do-isolamento/>. Acesso em: 4 de jun. 2021.

10 Disponível em: <https://piaui.folha.uol.com.br/lupa/2020/12/30/informacoes-falsas-bolsonaro-covid19/>. Acesso em: 4 de jun. 2021.
} 


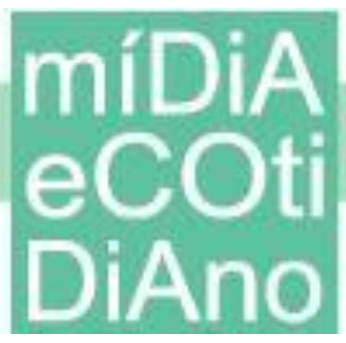

da pandemia, com a afirmação de que "estamos vivendo um finalzinho de pandemia" ${ }^{11}$, o apoio ao uso de medicamento ineficaz no tratamento da doença, pois "cada vez mais o uso da cloroquina se apresenta como algo eficaz" ${ }^{12}$ e falsas afirmações atribuídas à OMS, "após pedirem desculpas pela hidroxicloroquina, agora a OMS conclui que pacientes assintomáticos (a grande maioria) não têm potencial de infectar outras pessoas" ${ }^{13}$.

Conteúdos que promovem a negação da pandemia, que sugerem curas milagrosas ou medicamentos ineficazes para tratamento da doença e que contrariam medidas efetivas de prevenção à infecção, trazem riscos reais à saúde das pessoas. Dado que a crença em informações falsas se dá numa dimensão simbólica que se estende às práticas, assim, a falsa sensação de segurança compromete o cumprimento de orientações confiáveis para a própria proteção dos indivíduos.

Ademais, a disseminação de informações falsas pode ser impulsionada por pronunciamentos de atores políticos que possuem visibilidade na esfera social, a exemplo do presidente Jair Bolsonaro, com expressivo poder de reforço a narrativas que legitimam a desinformação. Nesse sentido, alerta-se que “[...] a polarização política e a desinformação sobre as temáticas relacionadas à doença tornaram-se um problema no controle do vírus no Brasil” (RECUERO et. al., 2020, p. 4).

\section{Movimentos antivacina e a negação da vida}

A busca pelo desenvolvimento e produção de vacinas foi intensificada em todo o mundo com o objetivo de controlar o vírus. Vasconcellos-Silva e Castiel (2020) enfatizam que a imunização da população é considerada um importante advento biotecnológico no controle de doenças e redução de mortes por epidemias. Apesar disso, a politização, a desinformação e o negacionismo também alcançaram a vacinação contra a Covid-19.

\footnotetext{
${ }^{11}$ Fala de Jair Bolsonaro durante evento no Rio Grande do Sul em 10 de dezembro de 2020. Disponível em: <https://piaui.folha.uol.com.br/lupa/2020/12/30/informacoes-falsas-bolsonaro-covid-19/>. Acesso em: 4 de jun. 2021.

12 Tweet de Jair Bolsonaro publicado em 8 de abril de 2020. Disponível em: <https://piaui.folha.uol.com.br/lupa/2020/12/30/informacoes-falsas-bolsonaro-covid-19/>. Acesso em: 4 de jun. 2021.

13 Tweet de Jair Bolsonaro publicado em 8 de junho de 2020. Disponível em: <https://piaui.folha.uol.com.br/lupa/2020/12/30/informacoes-falsas-bolsonaro-covid-19/>. Acesso em: 4 de jun. 2021.
} 
Não obstante, a desconfiança em relação às vacinas está enraizada em acontecimentos que antecedem a pandemia. Shimizu (2018) evidencia que, no contexto mundial da Segunda Revolução Industrial, o Brasil passava por mudanças para acompanhar as transformações e havia o interesse de atrair investidores e turistas para a cidade do Rio de Janeiro, considerada a vitrine do país.

De acordo com a autora, a região sofreu uma política de remodelação urbana, uma vez que ainda apresentava características coloniais e surtos de doenças. Para acelerar o processo, o governo instaurou a imunização contra a varíola, doença que vitimava milhares de pessoas na época, de maneira compulsória, uma campanha marcada pela chamada Revolta da Vacina, no ano de 1904.

A agitação popular que, por fim, culminou com a Revolta da Vacina, foi estimulada em grande parte por políticos de oposição ao governo e pela imprensa não governista que dava voz às declarações de figuras públicas respeitadas que eram contrárias à lei da vacina. Esses discursos defendiam o direito à liberdade de escolha do cidadão, criticavam a obrigatoriedade da vacinação, e colocavam em dúvida sua segurança, chamando-a de injeção de "veneno" (SHIMIZU, 2018, p. 88).

De acordo com Vasconcellos-Silva e Castiel (2020), há exemplos de conflitos entre as intervenções públicas para vacinação e as narrativas morais, inclusive aquelas ligadas às liberdades individuais.

$\mathrm{Na}$ Inglaterra de 1853, o Compulsory Vaccination Act despertou a ira da classe média alta - um ultraje à liberdade de arbitrar sobre o estado imunológico dos filhos. Algo semelhante aconteceu no final do século $\mathrm{XX}$, quando a Internet já ampliava vertiginosamente seu poder de influência e acesso a fontes primárias de comunicação científica entre diversos segmentos sociais. [...] Em 1998, o médico Andrew Wakefield tornou público no periódico Lancet um artigo sugerindo que a vacina MMR contra sarampo, caxumba e rubéola predisporia à exposição ao mercúrio e ao autismo. Apesar do pequeno tamanho da amostra (12 crianças), o desenho não controlado e a natureza especulativa das conclusões, o paper ofereceu uma potente narrativa de risco cientificamente validado para o movimento antivacinação e isto acrescentou novos monstros ao cenário da saúde pública. (VASCONCELLOS-SILVA; CASTIEL, 2020, p. 6). 
Para Souza et. al. (2020) mesmo os periódicos de confiabilidade "incontestável” podem disseminar desinformação com consequências desastrosas. Os autores consideram que a publicação no periódico The Lancet foi a gênese do movimento global antivacina, pois mesmo depois da revista ter lançado um editorial reconhecendo o equívoco do estudo sobre a vacina MMR, publicado em 1998, a ressonância provocada foi capaz de diminuir a cobertura vacinal em diversos países até hoje. Acrescenta-se que o caso, revelado pelo jornalista Brian Deer, então repórter do The Sunday Times, mostrava que "a invenção de que as vacinas causam autismo escondia, na verdade, um conflito de interesse grave do então médico, o qual desejava patentear uma vacina própria" (CANCIAN, 2020, p. 54).

Considerando o cenário nacional, Almeida e Quadros (2020) indicam que os questionamentos sobre a eficácia e a segurança das vacinas no Brasil seguem aumentando. Para elas, essa noção é facilmente percebida pelo crescimento de grupos que divulgam conteúdos antivacinação nas mídias sociais, especialmente no Facebook, em que foram criadas 18 comunidades com a temática antivacinação entre 2014 e 2019. As autoras destacam que esse tipo de publicação demonstra a desconfiança sobre a eficácia das vacinas, assim como a crença "de que os imunizantes são, na verdade, os causadores das doenças que deveriam proteger; a desconfiança sobre as substâncias que compõem as vacinas; e os reais propósitos de quem impõe a vacinação em massa" (ALMEIDA; QUADROS, 2020, p. 106).

O crescente movimento antivacinação também é associado ao "resultado da relação entre o fenômeno da prática do autocuidado, o horário limitado do funcionamento dos postos de vacinação e a dificuldade no transporte e na armazenagem das vacinas, além da desinformação e da hesitação em vacinar” (RIBEIRO, 2020, p. 42). Uma conjunção de fatores, em que se inclui a desinformação, que desperta o receio diante da vacinação. Para a autora, essa condição já ameaça reverter o progresso no combate às doenças evitáveis por imunização, principalmente nos países em desenvolvimento. Como no caso do sarampo, em que foi registrado um aumento de $30 \%$ nos casos de infecção em todo o mundo. No Brasil, indica-se que:

Até 2016 o Brasil tinha a certificação da Organização Pan-Americana da Saúde por ter controlado absolutamente o sarampo em todo o 
território nacional. Certificação essa que foi suspensa no início de 2019, com mais de 200 casos registrados na época. Atualmente, só em São Paulo foram realizados cerca de mil registros da doença. (RIBEIRO, 2020, p. 43).

Já em relação à pandemia da Covid-19, destaca-se a pesquisa de título "Desinformação, Covid-19 e a Mídia Social no Brasil" realizada pelo laboratório MIDIARS, de março a dezembro de 2020, que identificou desinformação e negacionismo sobre a vacinação contra a doença. Como exemplo, os pesquisadores evidenciam o enquadramento político da vacina do Instituto Butantan, que utiliza insumos chineses em sua produção, ao aumento da discussão sobre a origem das vacinas como um critério para comprovação de sua eficácia. A partir dessa relação, foi possível identificar, de modo frequente, a presença de posicionamentos antivacina em grupos radicalizados nas mídias sociais.

Esse posicionamento, legitimado pelos grupos, fortalece a narrativa conspiratória de que a vacina não funcione e não tenha eficácia, sendo apenas uma construção para mudar o foco das mortes. A vacina aparece também como mais uma parte de um complô da China na fabricação e disseminação do vírus, que agora lucraria também com a oferta da vacina. (RECUERO et. al., 2021, p. 29).

A partir disso, os autores alertam que a desconfiança gerada é relevante e abrangente, principalmente por enquadrar o ato de vacinação como uma ação políticopartidária. Assim, "os efeitos do descrédito das vacinas podem ainda perdurar por um longo prazo, gerando também efeitos negativos em futuras campanhas de vacinação na população brasileira" (RECUERO et. al., 2021, p. 30). Nota-se que a desinformação é capaz de reforçar a ambiência negacionista direcionada à vacinação contra a Covid-19. Que pode ser ainda mais danosa quando emitida por agentes públicos, dada a sua influência na sociedade, visto que chancelam a recusa a um imunizante que garante proteção contra um vírus causador de tantas mortes, atuando assim na negação da própria vida.

\section{Infodemia e Políticas de Morte}


Em um cenário infodêmico, o discurso do presidente Jair Bolsonaro tem conduzido um manual de infoxicação ${ }^{14}$, semeando dúvidas e conspirações na população. "Vacinas chinesas" não são confiáveis. Quem já foi infectado pelo novo coronavírus não precisa se vacinar. Efeitos colaterais graves. "Morte, invalidez, anomalia. Esta é a vacina que o Doria queria obrigar todos os paulistanos a tomá-la. O presidente disse que a vacina jamais seria obrigatória. Mais uma que Jair Bolsonaro ganha” 15 (grifo nosso). Declarações que aumentam a insegurança. De acordo com o estudo, Conspiracy Beliefs, Rejection of Vaccination, and Support for hydroxychloroquine: A Conceptual Replication-Extension in the COVID-19 Pandemic Context ${ }^{16}$, existe uma relação direta entre acreditar em desinformações e rejeitar uma vacina contra a Covid-19. Uma escolha privada e ideológica com impactos na saúde coletiva.

Como uma doutrina, assente em uma apropriação do discurso do Outro, seu eleitorado "têm por norma obedecer e acreditar naquilo que é dito pelo seu chefe e, assim, lutar pelo sonho de sociedade que está no imaginário de um governo de extrema-direita, na qual o coronavírus é uma fantasia" (SOARES JÚNIOR, 2020, p. 114). Em sentido complementar, indica-se que "é pela partilha de um só e mesmo conjunto de discursos que indivíduos, tão numerosos quanto se queira imaginar, definem sua pertença recíproca" (FOUCAULT, 2014, p. 39-40). Pela identificação e valorização dos iguais, cria-se uma prática excludente, uma governamentalidade com características fascistas (ECO, 2018). “Assim, os discursos do chefe do Poder Executivo não são desprovidos de intencionalidades, ao contrário, cada uma de suas expressões funcionam como um grande procedimento de sujeição, de alijamento, de sonoridades berrantes" (SOARES JÚNIOR, 2020, p. 115), para agregar e encorajar aliados que se tornaram os olhos, os braços e as armas que protegem o tirano.

\footnotetext{
14 Termo criado por Alfons Cornellá, em 1996, a partir da adjeção das palavras "informação" e "intoxicação", apontando um excesso de informação não "digerida" por completo.

15 Quando a Anvisa, Agência Nacional de Vigilância Sanitária, suspendeu por dois dias os testes da Coronavac, em novembro de 2020, até que fosse confirmada a desconexão entre a morte de um voluntário e o imunizante, Bolsonaro comemorou o episódio como uma vitória pessoal. Publicação no Twitter. Disponível em: <https://twitter.com/jornaldacbn/status/1326127878241742849/photo/1>. Acesso em: 14 jun. 2021.

${ }^{16}$ Disponível em: <https://psyarxiv.com/rz78k>. Acesso em: 14 jun. 2021.
} 
No dia 17 de dezembro de 2020, quando o país contabilizou 184.876 mortos e 7.111.527 casos diagnosticados com a doença ${ }^{17}$, durante um pronunciamento em um evento, o presidente fez as seguintes alegações, as quais subscrevemos:

A vacina uma vez certificada pela Anvisa vai ser extensiva a todos. Que [sic] quem não tomá-la? Eu não vou tomar. Alguns falam que eu tô [sic] dando um péssimo exemplo. Ôh, imbecil! (aplausos) O idiota que tá [sic] dizendo que eu dou um péssimo exemplo, eu já tive o vírus. Eu já tenho anticorpos. Pra que tomar vacina de novo? E outra coisa que tem que ficar bem claro aqui Dra. *** (não compreensível). Lá, na Pfizer, tá bem claro lá no contrato: nós não nos responsabilizamos por qualquer efeito colateral. Se você virar um jacaré, é problema de você [sic], pô! Não vou falar outro bicho, porque vou começar aqui a falar besteira aqui [sic], né? Se você virar Super-Homem, se nascer barba igual [sic] [em alguma] mulher, ou, ou, algum homem começar a falar fino, eles não tem nada a ver com isso. O que é pior: mexer no sistema imunológico das pessoas! Como você pode obrigar alguém a tomar uma vacina que não se completou a terceira fase? Ainda tá na experimental. E depois... Agora, parlamentar é pra vocês. Tem um projeto, uma medida provisória que chegou alterada pra mim, o artigo que dizia que a Anvisa tinha 72 horas para certificar. Se não certificasse, certificado estava. Eu vetei. O Congresso derrubou o veto. Estamos mexendo com vidas! Cadê a nossa liberdade? Que a gente fala tanto em liberdade. (aplausos) E outra coisa, quem não quiser tomar a vacina, se porventura contra *** (não compreensível), a vacina for comprovadamente eficaz lá na frente, que a gente não sabe ainda, a responsabilidade é deles ${ }^{18}$. (BOLSONARO, 2020).

Em uma análise sobre a epidemia de varíola e as campanhas de inoculação, a partir de 1720, e de vacinação, em 1800, o surto é apresentado como um "fenômeno amplamente endêmico, de mortalidade elevadíssima" (FOUCAULT, 2008, p. 76), no qual o número de mortos era de 1 a cada $7,782^{19}$. Doravante as análises quantitativas, "a doença vai deixar de ser compreendida naquela categoria que ainda era muito sólida, muito consistente, dentro do pensamento médico e da prática médica da época" (FOUCAULT, 2008, p. 79), apresentando-se como uma distribuição de casos,

\footnotetext{
${ }^{17}$ Brasil volta a superar mais de 1 mil mortes por Covid-19; 16 estados e o DF estão com tendência de alta. Disponível em: <https://g1.globo.com/bemestar/coronavirus/noticia/2020/12/17/casos-e-mortes-porcoronavirus-no-brasil-em-17-de-dezembro-segundo-consorcio-de-veiculos-de-imprensa.ghtml>. Acesso em: 14 jun. 2021.

${ }^{18}$ Disponível em: <https://www.youtube.com/watch?v=lBCXkVOEH-8>. Acesso em 15 jun. 2021.

${ }^{19}$ A taxa de mortalidade por COVID-19, no Brasil, é de 232,3 a cada 100 mil habitantes. Disponível em: <https://covid.saude.gov.br/>. Acesso em 15 jun. 2021.
} 


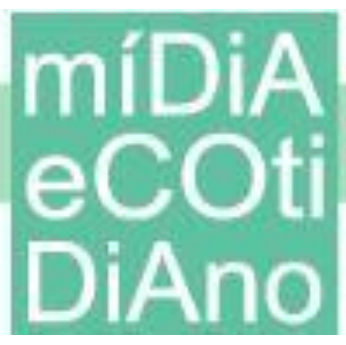

identificando os riscos para cada indivíduo, sua noção de perigo e fenômenos de disparada (ou momentos de crise), como conhecemos hoje. Uma disciplinaridade dos corpos, em uma anátomo-política ${ }^{20}$, assim como a própria administração da vida em sua governamentalidade. Por anátomo-política, conceito trabalhado por Foucault na década de 70, em seus estudos genealógicos, o exercício do poder dá-se no disciplinamento e castigo aplicados ao corpo do indivíduo (separação, alinhamento e uma série de vigilâncias). O governo das almas e do corpo produz, além do disciplinamento, verdades acerca do sujeito. Como aponta Foucault (2005), é na manutenção da vida que se exerce o poder.

Com a difusão do chamado tratamento precoce, à base de medicamentos como hidroxicloroquina (para malária) e ivermectina (vermífugo), o líder governamental, alvitrando dúvidas, nega a vacina, “eu não vou tomar”, justificado pela certeza de que não seria possível uma reinfecção. “O idiota que tá $[s i c]$ dizendo que eu dou um péssimo exemplo, eu já tive o vírus. Eu já tenho anticorpos. Pra que tomar a vacina de novo?”. A reinfecção pelo novo coronavírus já foi comprovada cientificamente. "Temos cepas que apresentam maior capacidade de transmissibilidade circulando em todo país, principalmente a P.1 [de Manaus]. Como elas são transmitidas com muito mais facilidade, há um risco maior de quem já teve a infecção possa adquirir novamente" ${ }^{21}$ (ROCHA, 2021). O estudo Genetic evidence and host immune response in persons reinfected with SARS-CoV-2 $2^{22}$, desenvolvido por pesquisadores da Fundação Oswaldo Cruz, mostra ainda que a segunda infecção por Covid-19 pode provocar sintomas mais fortes que a primeira. Nessa esteira, "nega-se [...] qualquer voz, vinda da ciência e veiculada pelas diversas mídias, que contrarie a ideologia propulsora do negacionismo" (LOPES, 2021, p. 105).

\footnotetext{
${ }^{20}$ A anátomo-política, instaurada no decorrer do século XVIII, refere-se aos dispositivos disciplinares que incidem sobre o corpo, a fim de extrair sua força produtiva, mediante o controle.

${ }^{21}$ Rodrigo Molina, infectologista e professor da Universidade Federal do Triângulo Mineiro (UFTM). 7 fatos sobre reinfecção pela Covid-19. Disponível em: <https://www.cnnbrasil.com.br/saude/2021/04/15/7-fatos-sobre-reinfeccao-pela-covid-19>. Acesso em: 15 jun. 2021.

${ }^{22}$ Disponível em: <https://wwwnc.cdc.gov/eid/article/27/5/20-4912_article>. Acesso em: 15 jun. 2021.
} 
Contra a vacinação e sua obrigatoriedade, o presidente incentiva o movimento antivacina. "Vacina obrigatória só aqui no Faísca" ${ }^{23}$. Na contramão da biopolítica, uma vez que a vacinação é um dos seus dispositivos de segurança, o discurso governamental expõe suas garras soberanas e gerencia a morte. "Tais formas da soberania estão longe de ser um pedaço de insanidade prodigiosa ou uma expressão de alguma ruptura [...]. De fato, tal como os campos da morte, são elas que constituem o nomos ${ }^{24}$ do espaço político em que ainda vivemos" (MBEMBE, 2018, p. 11).

Imerso em uma necrobiopolítica, que é uma forma de governamento, mas também um discurso, declara: "Se você virar um jacaré, é problema de você [sic], pô! Não vou falar outro bicho, porque vou começar aqui a falar besteira aqui [sic], né? Se você virar Super-Homem, se nascer barba igual [sic] [em alguma] mulher, ou, ou, algum homem começar a falar fino". A farmacêutica que não se responsabiliza pelos efeitos colaterais da vacina, poderia, no dito do presidente, transformar indivíduos em animais, em um homem com poderes sobrenaturais, ou mudar o seu gênero. Em História da sexualidade: a vontade de saber, Foucault "aponta para a normatização das práticas sociais a partir das relações de saber-poder, que as codificam segundo um regime de verdades misógino, preconceituoso e excludente, justificando a heteronormatividade compulsória e a lesbofobia” (RAGO, 2020, p. 212). Se a morte não acontece no corpo, ela já começa nas palavras. O chefe do Executivo provoca: "eles não têm nada a ver com isso". Eles, a Pfizer, não se responsabilizam pelos "prejuízos", pelas "faltas", pelos “danos" causados. "Parece-me que encontramos aí, da soberania infame à autoridade ridícula, todos os graus do que poderíamos chamar de indignidade do poder" (FOUCAULT, 2001, p. 16).

Em inúmeros momentos, o presidente levanta dúvidas sobre a eficácia da vacina: "uma vez certificada pela Anvisa", "mexer no sistema imunológico", "não completou a terceira fase", "que a gente não sabe ainda". Embora atuar no sistema imunológico seja o principal objetivo da vacinação, uma vez que estimula o sistema imune a produzir anticorpos, como um dispositivo de segurança e prevenção, a informação apresenta uma

\footnotetext{
${ }^{23}$ Publicação do presidente Jair Bolsonaro, no Twitter, fazendo referência ao seu cachorro. Disponível em: <https://twitter.com/jairbolsonaro/status/1320132151690645504>. Acesso em: 14 jun. 2021.

${ }^{24}$ Nomos é, na mitologia grega, o daemon das leis, estatutos e normas.
} 


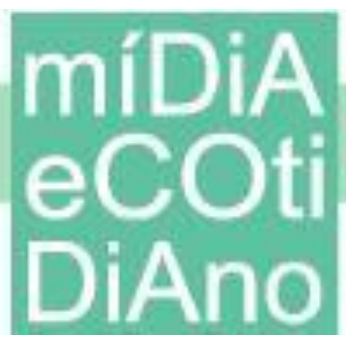

conotação negativa, "segundo o qual as vacinas são formas de prevenção com eficácia não comprovada e/ou com ação prejudicial ao organismo dos indivíduos, os quais poderiam, no limite, ter um chip implantado em seus corpos e seus DNAs alterados como uma intervenção diabólica" (LOPES, 2021, p. 109). O próprio Congresso também é questionado, quando retrata: “Tem um projeto, uma medida provisória que chegou alterada pra mim, o artigo que dizia que a Anvisa tinha 72 horas para certificar. Se não certificasse, certificado estava. Eu vetei. O Congresso derrubou o veto" (grifo nosso). O uso da palavra alterada, nesse contexto, indica um ato fraudulento, espúrio, desequilibrado dos parlamentares, visto que "estamos mexendo com vidas".

Nesse ponto, recorre à liberdade. "Cadê a nossa liberdade? Que a gente fala tanto em liberdade". Favorecendo-se de um discurso libertário, parte de uma abnegação do eixo soberano-súditos, como uma estratégia de proibição, em que os mecanismos de segurança não podem funcionar. Entretanto, esquece que, no âmbito da população, é preciso "deixar as circulações se fazerem, controlar as circulações, [...] fazer que as coisas se mexam, se desloquem sem cessar, que as coisas vão perpetuamente de um ponto a outro, mas de maneira tal que os perigos inerentes a essa circulação sejam anulados" (FOUCAULT, 2008, p. 85). É possível constatar que, apesar de utilizar a expressão “a gente”, o presidente fala a um Outro que reivindica. Um momento em que é aclamado. São dois instantes em que surgem aplausos, quando insulta um crítico do seu comportamento de “imbecil” e nessa fala. No processo no qual Foucault (apud DEYFUS; RABINOW, 1995, p. 231) denomina como "práticas divisoras" ${ }^{25}$, estabelecemos uma alteridade, um Outro que é estrangeiro e, portanto, um inimigo, que precisa ser ridicularizado, banido, agredido; eventualmente, morto. Se "a vacina for comprovadamente eficaz lá na frente, [...] a responsabilidade é deles" (grifo nosso). Nas suas próprias palavras, o sucesso pela vacinação também seria do Outro: da Pfizer, de quem acreditou. Deles.

\section{Considerações finais}

\footnotetext{
25 “O sujeito é dividido no seu interior e em relação aos outros. Este processo o objetiva. Exemplos: o louco e o são, o doente e o sadio, os criminosos e os "bons meninos"'. (FOUCAULT apud DREYFUS; RABINOW, 1995, p. 231).
} 
A desinformação não é apenas um problema de comunicação, mas também uma questão que assola os âmbitos governamentais em todas as suas esferas. Corresponde a um fenômeno complexo, dinâmico e persistente. Alcança diferentes esferas sociais e, no campo governamental, pode se tornar instrumento para manipulação da opinião pública sobre determinadas temáticas. A instauração do engano, a fim de justificar práticas nebulosas e narrativas populistas fundamentadas pelo fascismo (ECO, 2018), ameaça a própria vida. "Nesse caso, reflito sobre uma história que ainda não possui um final, mas cenas bordadas com a lâmina do medo, da agulha da dor e do bisturi da morte" (SOARES JÚNIOR, 2020, p. 98). É fato que, quando o chefe do Poder Executivo nega um dispositivo de segurança, constituinte da biopolítica, resolve-se, então, aderir a uma nova estratégia de governamento. Quando há uma recusa sistemática para a administração da vida, a única alternativa é a gerência da morte.

De acordo com a CPI da Covid-19 no Senado, 81 e-mails foram enviados pela Pfizer ao governo federal, entre março de 2020 e abril de 2021, sem obtenção de resposta. O governo que, em 17 de dezembro de 2021, levantou dúvidas sobre a eficácia da vacina e a responsabilidade da farmacêutica, três meses depois, fechou o primeiro contrato ${ }^{26}$. É importante lembrar que março de 2021 foi o mês com maior número de mortes registradas, desde o início da pandemia, somando $58.675^{27}$. Se a vacina era tão prejudicial quanto o discurso afirmava, uma mudança em pouco tempo, decerto, possa intuir que não havia uma crença efetiva na informação, mas uma escolha privada com intenções políticas, um emprego deliberado de desinformação que conduziu parte da população para a morte.

“As maneiras de matar não variam muito. No caso particular dos massacres, corpos sem vida são rapidamente reduzidos à condição de simples esqueletos. Sua morfologia doravante os inscreve no registo de generalidade indiferenciada: simples relíquias de uma dor inexaurível” (MBEMBE, 2018, p. 60). Pessoas que se tornam dados

\footnotetext{
${ }^{26}$ Após ignorar e-mails da Pfizer, Bolsonaro agora pede antecipação da entrega de doses. Disponível em: <https://www1.folha.uol.com.br/equilibrioesaude/2021/06/apos-ignorar-emails-da-pfizer-bolsonaroagora-pede-antecipacao-da-entrega-de-doses.shtml>. Acesso em: 18 jun. 2021.

27 Março teve todos os 31 dias em que a covid mais matou no Brasil. Disponível em: <https://www.poder360.com.br/coronavirus/marco-teve-todos-os-31-dias-em-que-a-covid-mais-matouno-brasil/>. Acesso em: 18 jun. 2021.
} 
estatísticos. Nesse artigo discutimos a infodemia e a desinformação, no âmbito da necrobiopolítica a qual vivemos, em um exercício de comunicação e poder. Um ato biopolítico para a segurança e defesa da vida.

\section{Referências}

ALMEIDA, A., QUADROS, C. Movimento antivacinas na internet: da apropriação e recirculação do jornalismo de saúde ao empoderamento de grupos no Facebook. Fake News e Saúde. Fundação Oswaldo Cruz. Gerência Regional de Brasília, Brasília, 2020.

AOS FATOS. Em três meses, desinformação sobre Covid-19 foi de cura milagrosa à politização do isolamento. Disponível em: <https://www.aosfatos.org/noticias/em-tres-mesesdesinformacao-sobre-covid-19-foi-de-cura-milagrosa-a-politizacao-do-isolamento/>. Acesso em: 4 de jun. 2021.

BARCELOS, T., MUNIZ, L.; DANTAS, D.; JUNIOR, D.; CAVALCANTE, J.; FAERSTEIN, E. Análise de fake news veiculadas durante a pandemia de COVID-19 no Brasil.

Disponível em: <https://www.scielosp.org/pdf/rpsp/2021.v45/e65/pt>. Acesso em: 12 de jun. 2021.

CAPONI, S. Covid-19 no Brasil: entre o negacionismo e a razão neoliberal. Disponível em: <https://www.scielo.br/j/ea/a/tz4b6kWP4sHZD7ynw9LdYYJ/abstract/?lang=pt>. Acesso em: 10 de jun. 2021.

CANCIAN, N. Vacinas, fake news e o papel do jornalista de saúde. Fake News e Saúde. Fundação Oswaldo Cruz. Gerência Regional de Brasília, Brasília, 2020.

COUTO, M.; BARBIERI, C.; MATOS, C. Considerações sobre o impacto da covid-19 na relação indivíduo-sociedade: da hesitação vacinal ao clamor por uma vacina. Disponível em: 〈https://www.scielo.br/j/sausoc/a/rQFs3PMLgZprt3hkJMyS8mN/?lang=pt>. Acesso em 11 de jun. 2021.

DREYFUS, H.; RABINOW, P. Michel Foucault, uma trajetória filosófica; para além do estruturalismo e da hermenêutica. Trad. Vera Porto Carrero. Rio de Janeiro: Forense Universitária, 1995.

ECO, U. O fascismo eterno. 1. ed. Rio de Janeiro: Record, 2018.

FOUCAULT, M. Os anormais: curso no Collège de France (1974-1975). Trad. Eduardo Brandão. São Paulo: Martins Fontes, 2001.

Em defesa da sociedade: curso no Collège de France (1975-1976). Trad. Maria Ermantina Galvão. São Paulo: Martins Fontes, 2005.

. Segurança, território, população: curso dado no Collège de France (1977-1978). Trad. Eduardo Brandão. São Paulo: Martins Fontes, 2008. 
A ordem do discurso: aula inaugural no Collège de France, pronunciada em 2 de dezembro de 1970. Trad. Laura Fraga de Almeida Sampaio. 24 ed. São Paulo: Edições Loyola, 2014.

LOPES, C. R. A biopolítica do risco e o discurso negacionista sobre vacinação contra Covid-19. Porto das Letras, 7(2), 2021. p. 103-117. Disponível em:

<https://sistemas.uft.edu.br/periodicos/index.php/portodasletras/article/view/11556>. Acesso em: 15 jun. 2021.

MBEMBE, A. Necropolítica. 4 ed. São Paulo: n-1 edições, 2018.

OPAS. Organização Pan-Americana da Saúde. Disponível

em: <https://www.paho.org/bra/index.php?option=com_content $\&$ view=article \&id=6101:covid 19\&Itemid=875>. Acesso em: 4 de jun. 2021.

RAGO, M. Feminismos e resistências: viver diferentemente o presente. In: BRAGA, A. (org.) et al. Por uma microfísica das resistências: Michel Foucault e as lutas antiautoritárias da contemporaneidade. 1 ed. Campinas, SP: Pontes Editores, 2020. p. 207-227.

RECUERO, R; SOARES, F.; VINHAS, O.; VOLCAN, T.; ZAGO, G.; STUMPF, E.; VIEGAS, P.; HÜTTNER, L.; BONOTO, C.; SILVA, G.; PASSOS, I.; SALGUEIRO, I.; SODRÉ, G.

Desinformação, Mídia Social e Covid-19 no Brasil. [livro eletrônico] Relatório, resultados e estratégias de combate. 1. ed. - Pelotas, RS: MIDIARS - Grupo de Pesquisa em Mídia Discurso e Análise de Redes Sociais, 2021.

RECUERO, R., SOARES, F., ZAGO, G. Polarização, Hiperpartidarismo e Câmaras de Eco: Como circula a Desinformação sobre Covid-19 no Twitter. Disponível em:

<https://periodicos.uff.br/contracampo/article/view/45611>. Acesso em 5 de jun. 2021.

ROCHA, L. 7 fatos sobre reinfecção pela Covid-19. CNN, 2021. Disponível em: <https://www.cnnbrasil.com.br/saude/2021/04/15/7-fatos-sobre-reinfeccao-pela-covid-19>. Acesso em: 15 jun. 2021.

SOARES JÚNIOR, A. Histórias de resistências ao coronavírus e ao vírus do autoritarismo. In: BRAGA, A. (org.) et al. Por uma microfísica das resistências: Michel Foucault e as lutas antiautoritárias da contemporaneidade. 1 ed. Campinas, SP: Pontes Editores, 2020. p. 95-123.

SOUZA, G., ALMEIDA, T. OLIVEIRA, Y. Fake news em saúde e mídias sociais: como funcionam, quais seus impactos e possíveis soluções. Fake News e Saúde. Fundação Oswaldo Cruz. Gerência Regional de Brasília, Brasília, 2020.

\section{SHIMIZU, N. MOVIMENTO ANTIVACINA: A MEMÓRIA FUNCIONANDO NO/PELO (PER)CURSO DOS SENTIDOS E DOS SUJEITOS NA SOCIEDADE E-URBANA.}

Revista do EDICC [online]. 2018, v. 5, n. 5. Disponível em:

<https://revistas.iel.unicamp.br/index.php/edicc/article/view/5963>. Acesso em: 23 de set. 2021. VASCONCELLOS-SILVA, P., CASTIEL, L. COVID-19, as fake news e o sono da razão comunicativa gerando monstros: a narrativa dos riscos e os riscos das narrativas. Cadernos de Saúde Pública [online]. 2020, v. 36, n. 7. Disponível em: <https://doi.org/10.1590/0102311X00101920>. Acesso em: 7 de jun. 2021. 
WARDLE, C. Fake News. It's Complicated. 2017. Disponível em:

<https://firstdraftnews.com/fake-news-complicated/>. Acesso em: 4 de jun. 2021.

WARDLE, C.; DERAKSHAN, H. Information Disorder: Toward an interdisciplinary

framework for research and policy making. Strasbourg: Council of Europe. 2017. 